\title{
Characterization of Blends of Virgin Nitrile Rubber and Compounded Nitrile Rubber Latex Waste Reclaimed with Urea: Part II - Physico-Mechanical Properties
}

\author{
K.I.D.P. Perera ${ }^{1,2, *}$, D.G. Edirisinghe1, Laleen Karunanayake² \\ ${ }^{1}$ Rubber Technology and Development Department, Rubber Research Institute of Sri Lanka, Telawala Road, Ratmalana - 10390, Sri Lanka. \\ ${ }^{2}$ Department of Polymer Science, University of Sri Jayewardenepura, Gangodawila, Nugegoda - 10250, Sri Lanka.
}

\section{A R T IC LE DET A I L S}

Article history:

Received 03 May 2021

Accepted 04 June 2021

Available online 25 June 2021

\section{Keywords:}

Mechano-Chemical Reclaiming

Nitrile Rubber (NBR)

Rubber Blends

Oil Resistant Applications

\begin{abstract}
A B S T RAC T
Recycling of rubber waste materials in order to convert these to usable products is one of the main challenges in the rubber industry. Reclaiming of rubber waste and blending it with virgin rubber have increased during the past due to the growing concern on the environment and increase in the prices of synthetic rubbers. Hence, the aim of this study is to partially replace virgin nitrile rubber (NBR) with reclaimed compounded NBR latex waste to develop new rubber blends suitable for special applications. In this study, physico-mechanical properties, ageing performance and swelling behaviour of virgin NBR / reclaimed NBR blend vulcanizates were evaluated and compared with those of the control vulcanizate produced solely with virgin NBR. Results showed that replacement of 50\% virgin NBR with reclaimed NBR retained $71-86 \%$ of tensile strength, elongation at break and resilience. Hardness and modulus of this blend vulcanizate increased by less than $18 \%$, whereas abrasion volume loss and compression set increased by $27 \%$. Ageing resistance is similar to that of the control vulcanizate. Interestingly, resistance to swelling in toluene and ASTM oil No.3 increased by $14 \%$ and 32\%, respectively. Hence, the 50:50 virgin NBR / reclaimed NBR vulcanizate would be suitable for oil resistant applications.
\end{abstract}

\section{Introduction}

Development of science-based technologies and processes for rubber recycling, and the use of recycled rubbers in end-products, would significantly reduce worldwide energy consumption, provide renewable rubbers from rubber waste and lead to less pollution of the environment. Considering the economic and environmental advantages, recycling is one of the best options. The use of acrylonitrile-butadiene rubber or nitrile rubber (NBR) latex in glove production has increased all over the world due to its excellent resistance to puncture and tear as well as the nonexistence of leachable allergenic proteins, unlike in natural rubber latex. Nitrile gloves are currently used in many areas such as the medical field and, to a greater extent, the food industry, automotive industry, etc. As a result, significant quantities of compounded rubber waste and discarded gloves are generated worldwide daily [1]. Compared with NBR glove waste, compounded NBR latex waste is lightly crosslinked and have the high quality nature of rubber hydrocarbon. Quantities of rubber waste are generated worldwide daily due to many reasons such as, not meeting processing and product specifications, leftover rubber from manufacturing activities and also old and defective rubber products such as gloves, catheters, tubes, old tires, etc. NBR is widely used due to oil and heat resistance, low gas permeability and high shear strength for structural applications. However, after a certain period of time these polymeric materials are not useable and mostly discarded.

The use of waste/recycled rubber in polymer blends has commonly been carried out. These blends can be used to manufacture a wide range of products such as playground surfaces, recycled rubber flooring and sporting mats [2]. Blends of rubber waste with a number of polymers have given poor properties owing to weak interfacial adhesion between the crosslinked waste rubber and the polymer. Therefore, modification of waste rubber has been carried out in the past with the aim of enhancing adhesion between the two phases, waste rubber and polymer matrix [3]. The different modification processes carried out in the past were reviewed and reported in Part-I of this study [4].

Blending of ground rubber tyre (GRT) with a number of polymers has given poor properties owing to weak interfacial adhesion between the

*Corresponding Author:indikaperera.ou@gmail.com(K.I.D.P. Perera)

crosslinked GRT particles and the polymer [5, 6]. Ramarad and co-workers [7] reviewed that waste tire rubber in the form of ground particles can be incorporated with polymer materials and reclaimed rubber. Natural rubber (NR) / reclaimed GRT blends were prepared by Edirisinghe et al. [8]. They reported that abrasion volume loss of blends of 85:15 virgin NR / novel reclaimed rubber (produced with an amino compound) revulcanizates is lower than that of the revulcanizate prepared with a blend of 85:15 virgin NR / reclaimed rubber available locally and comparable to that of the $100 \%$ NR vulcanisate (control). According to them, tensile strength and elongation at break of the virgin NR / novel reclaimed rubber revulcanizates were lower than those of the control vulcanizate. However, these values were at a level acceptable for tyre treads. Myhre and Mackillop [9] evaluated the effect of blending virgin NR with 40 and $60 \%$ devulcanised rubber (DVR) on physico-mechanical properties of NR/DVR blends. When DVR was added to NR, there was a reduction in tensile properties. However, properties were quite good even at a level of 40 parts. Hence, this blended rubber can be used to manufacture many products. However, tear strength of the blends was comparable to that of virgin NR. Furthermore, a great reduction in volume swell was observed in the presence of the DVR in comparison with the $100 \%$ NR compound. Theodore et al. [10] have reported cure and mechanical properties of elastomeric compounds containing devulcanized material. Nuzaimah et al. [11] reported surface treatment of rubber crumbs conducted after grinding the waste gloves under cryogenic conditions and composites were fabricated by adding the treated rubber to the unsaturated polyester. The $\mathrm{NaOH}$ treated waste rubber crumbs improve adhesion between rubber and polyester, which increases the tensile strength of the composite.

Surface modification of GRT powder was carried out by Zhang et al. [12] to enhance its adhesion to NBR. In the surface treatment process, the hydrophobic surface of GRT powder has been transformed to a hydrophilic one through atmospheric pressure dielectric barrier discharge (DBD). Surface modified GRT/NBR blends show improved mechanical properties, which can be attributed to increase interfacial bonding between modified GRT and NBR. Also, Ahmad et al. [13] have reported that compatibility of NR with NBR glove waste can be improved by incorporating epoxidized natural rubber (ENR) in NR/NBR blends.

Styrene-butadiene rubber (SBR) / recycled NBR glove waste (NBRr) blends were developed by Noriman et al. [14] to enhance compatibility of SBR/NBRr blends by incorporating TOR (trans-polyoctylene rubber).

\footnotetext{
(2.
} 
Tensile strength, tensile modulus, and hardness increased, but elongation at break and rebound resilience have been reduced in SBR/NBRr blends. Thermo gravimetric analysis (TGA) and differential scanning calorimetry (DSC) were carried out on SBR/NBRr blends by Noimam and co-workers [15]. Results showed that incorporation of the small size NBRr provided more surface area to interact with SBR polymers thus increasing the state of crosslinking. The effects of different sizes of NBRr and blend ratios on curing characteristics, mechanical properties and morphological properties of SBR/NBRr blends have been already published [16].

Ternary blends of NR/SBR/recycled nitrile glove (NBRr) have been prepared by Nik Yahya et al. [17]. They have studied the effects of different particle sizes of NBRr on curing characteristics and physical properties of NR/SBR/NBRr blends. The rigidity of NR/SBR/NBRr blends increased when smaller NBRr particles were used, which explained the increase in hardness and decrease in resilience of the blends.

The effect of blend composition and dynamic vulcanization on processability, mechanical properties, swelling behavior, and morphology of virgin poly(vinylchloride)/acrylonitrile- butadiene rubber (PVCv/NBR) and waste poly(vinylchloride)/acrylonitrile-butadiene rubber (PVCw/NBR) blends were investigated by Ismail et al. [18]. This study reveals that $\mathrm{PVCw} / \mathrm{NBR}$ blends have higher stabilization torque, mechanical energy, and swelling index, but lower mechanical properties than PVCv/NBR blends. Fazli et al. [19] have pointed out that thermoplastic elastomer compounds can be produced using waste rubber powder. A comprehensive review has been reported by Nuzaimah et al. [20] for recycling and reuse of waste rubber. They have reported that waste rubber gloves can be utilized as a reinforcement material or filler in polymeric material to form composites.

This paper is the second part of a study on blends of virgin NBR and reclaimed compounded NBR latex waste. This work compared the physico-mechanical properties of vulcanizates with those of the control vulcanizate. The first part paper [4] reported reclaiming compounded NBR latex waste with urea, which is a readily available, low-cost, environmentally friendly amino compound. The reclaimed compounded NBR latex waste thus produced was initially characterized for its properties

Thereafter, it was blended with virgin NBR and the resulting blend compounds were evaluated for cure characteristics and physical properties. Further, these properties of the blends were compared with those of the control. In the previous paper it has been concluded that slower curing behavior of the 50:50 virgin NBR / reclaimed NBR blend compound in comparison to the virgin NBR compound would make the blend suitable for the production of thin-walled non-polar oil resistant articles.

\section{Experimental Methods}

\subsection{Materials}

Compounded carboxylated NBR latex waste was used as the rubber waste material in this study. It was supplied by Holcim Lanka (Pvt.) Ltd., a cement manufacturing company, which uses this waste generated from the glove manufacturing industry in Sri Lanka, in their cement kilns as a source of heat energy. Commercial grade of urea purchased from Glorchem Enterprise, Sri Lanka was used as the reclaiming agent. Virgin NBR used for the study was a medium acrylonitrile content NBR with a Mooney viscosity of $40-45 \mathrm{ML}(1+4) 100{ }^{\circ} \mathrm{C}$ and it was purchased from Lanxess-Arlanxeo, China.

Zinc oxide, used as activator was purchased from POCL Enterprises Ltd., India. Stearic acid was used as co-activator and it was procured from PalmOleo Sdn. Bhd, Malaysia. Carbon black (N 330-high abrasion furnace black) was used as a reinforcing filler and it was supplied by Birla Carbon India Private Limited, India. Dioctyl phthalate (DOP) was obtained from Hanwha Chemical Co., Ltd., Korea and it was used as a processing-aid for NBR. TBBS (N-t-butyl-2-benzothiazole sulphenamide) and TMTD (tetramethylthiuram disulfide) were used as accelerators for sulfur vulcanization. TBBS and TMTD were purchased from Huangyan Zhedong Rubber Auxiliary, China. Sulfur used as the vulcanizing agent was obtained from Miwon Chemicals Co., Ltd, Korea. Flectol-H (1,2-dihydro2,2,4 trimethylquinoline) purchased from Glorchem Enterprises, Sri Lanka was used as antioxidant. Toluene $(99.5 \mathrm{wt} \%)$ was used as received and it was supplied by Sasol Limited, South Africa. ASTM oil No. 3 was used for the oil absorption test and it was supplied from Microcells (Pvt.) Ltd., Sri Lanka.

All the above-mentioned raw materials and rubber compounding ingredients were used in the preparation of the NBR blend compounds mentioned in Part-I of this study [4]. These blend compounds were subsequently vulcanized as described below for evaluation of physicomechanical properties.

https://doi.org/10.30799/jacs.238.21070301

\subsection{Preparation of Virgin NBR / Reclaimed NBR Blend Vulcanizates}

Seven virgin NBR / reclaimed NBR blend compounds were prepared by varying the reclaimed NBR content from $10-70 \%(\% \mathrm{w} / \mathrm{w})$ at $10 \%$ $(\% \mathrm{w} / \mathrm{w})$ intervals, namely $\mathrm{W}_{10}$ (90:10 virgin NBR/reclaimed NBR), $\mathrm{W}_{20}$ (80:20 virgin NBR/reclaimed NBR), $W_{30}$ (70:30 virgin NBR/reclaimed NBR), $\quad W_{40}\left(60: 40\right.$ virgin NBR/reclaimed NBR), $W_{50}$ (50:50 virgin NBR/reclaimed NBR), $W_{60}$ (40:60 virgin NBR/reclaimed NBR), $W_{70}$ (30:70 virgin NBR/reclaimed NBR) and the control compound, namely control NBR (100\% virgin NBR) was also prepared in Part-I [4] of this study. These compounds were placed in test piece moulds and pressed between the platens of a hydraulic press (Yeji Corporation, Taiwan). The samples were cured at $150{ }^{\circ} \mathrm{C}$ temperature and an applied pressure of $20 \mathrm{MPa}$ for the respective optimum cure times $\left(\mathrm{T}_{90}\right)$ obtained from rheographs. After curing, the test pieces were removed from the moulds and immediately cooled in water at ambient temperature $\left(27 \pm 2{ }^{\circ} \mathrm{C}\right)$ to prevent further curing.

\subsection{Measurement of Mechanical Properties of NBR Blend Vulcanizates}

An Instron 3300 Series (Instron Corporation, USA) material testing machine was used to measure the tensile properties of the vulcanizates in accordance with ISO $37: 2011$ at room temperature $\left(27 \pm 2{ }^{\circ} \mathrm{C}\right)$ at a grip separation rate of $500 \mathrm{~mm} / \mathrm{min}$. The tear strength of the vulcanizates was measured using nicked, crescent (die C) test pieces with the aid of the same machine as per ISO 34-1:2010 (E). The hardness of the vulcanizates was measured by a Digi Test (Bareiss, Germany) hardness tester for hardness on the IRHD N-scale as per ISO 48: 2010(E). The resilience of the vulcanizates was measured by a Wallace Lupke pendulum (Wallace Instruments, UK) in accordance with ISO 4662: 2009(E). Compression set at constant strain was measured according to ISO 815-1: 2014(E) test method. The abrasion resistance of the vulcanizates was determined using a DIN abrasion tester (Stech Engineers, Germany) in accordance with DIN 53516.

\subsection{Determination of Ageing Performance of the NBR Blend Vulcanizates}

An accelerated ageing test was performed in an air circulating ageing oven at $70 \pm 2{ }^{\circ} \mathrm{C}$ for $72 \mathrm{~h}$, and aged tensile properties and tear strength were measured as per IS0188:2011(E). Percentage retention (\%R) of the physico-mechanical properties was calculated as follows:

$$
\% R=\frac{P_{A}}{P_{U A}} X 100
$$

where, $\mathrm{P}_{\mathrm{UA}}$ is the unaged value of the property and $\mathrm{P}_{\mathrm{A}}$ is aged value of the property.

\subsection{Measurement of Swelling Behaviour of NBR Blend Vulcanizates}

Swelling measurements were carried out with toluene at room temperature $\left(27 \pm 2{ }^{\circ} \mathrm{C}\right)$. Vulcanised test pieces $(30 \mathrm{~mm} \times 10 \mathrm{~mm} \times 2 \mathrm{~mm})$ of the compounds were weighed accurately using an analytical balance and immersed in liquid for 3 days to attain equilibrium swelling. After attaining equilibrium swelling, the samples were taken out, the solvent was blotted from the surface of the vulcanisate using filter papers, and they were weighed immediately. Calculation of the change in mass, or, in other words, swelling (\%), was done in accordance with ASTM D471-479 as given below:

$$
\% \text { Swelling }=\frac{\left(M_{2}-M_{1}\right)}{M_{1}} \times 100
$$

where, $M_{1}$ is the initial mass of the specimen (g) and $M_{2}$ is the mass of the specimen after immersion (g).

\subsection{Measurement of Oil Absorbance of NBR Blend Vulcanizates}

Oil absorbance measurements were carried out with ASTM oil No 3 at room temperature $\left(27 \pm 2{ }^{\circ} \mathrm{C}\right)$. Vulcanized test pieces $(30 \mathrm{~mm} \times 10 \mathrm{~mm} \times$ $2 \mathrm{~mm}$ ) of the compounds were weighed accurately using an analytical balance and immersed in oil for 3 days to attain equilibrium oil absorption. After reaching the equilibrium absorbing of oil, the samples were taken out, the oil was blotted from the surface of the vulcanizate using filter papers, and it was weighed immediately. Calculation of the change in mass, or, in other words, oil absorbance (\%), was done in accordance with ASTM D471-479 as given below:

$$
\% \text { Oil absorbance }=\frac{\left(M_{2}-M_{1}\right)}{M_{1}} \times 100
$$

where, $M_{1}$ is the initial mass of the specimen (g) and $M_{2}$ is the mass of the specimen after immersion (g). 


\section{Results and Discussion}

\subsection{Mechanical Properties of NBR Blend Vulcanizates}

Fig. 1 shows that the hardness of virgin NBR / reclaimed NBR blend vulcanizates varies between 68-78 IRHD. Hardness increases with the increase of crosslink density [21]. This figure indicates that the vulcanizates containing the reclaimed material (except the vulcanizates containing $10 \%$ and $70 \%$ reclaimed rubber) possess higher hardness than the control, which does not contain any reclaimed rubber. Lower hardness shown by the vulcanizates containing $10 \%$ and $70 \%$ reclaimed rubber can be attributed to lower state of crosslinking and crosslink density as indicated by the maximum torque and (maximum-minimum) torque, respectively of virgin NBR/reclaimed rubber blend compounds [4] .

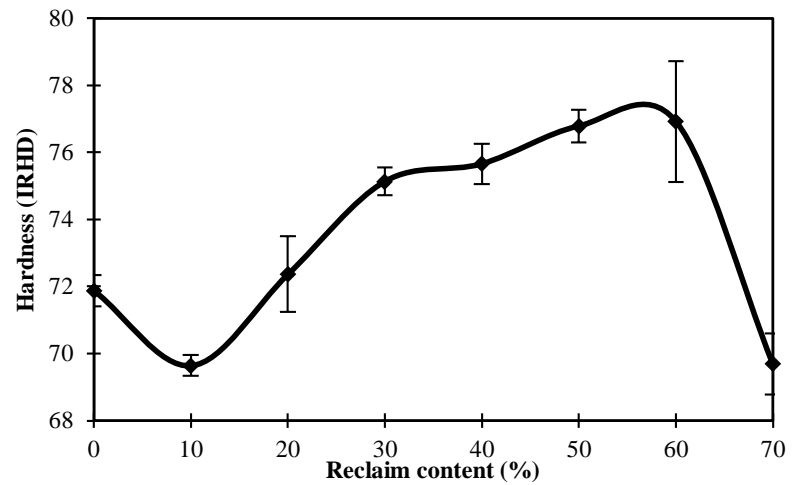

Fig. 1 Variation of hardness of virgin NBR / reclaimed NBR blend vulcanizates with reclaim content (NBR : nitrile rubber)

It is known that modulus at $100 \%$ elongation is a measure of stiffness or hardness of a vulcanizate. Hence as expected, variation of modulus at $100 \%$ elongation of blend vulcanizates with reclaim content (Fig. 2) is similar to the variation of hardness with reclaim content. Modulus is directly proportional to crosslink density [21] and with the increase of crosslink density, network becomes more elastic. As crosslink density increases, chain mobility decreases, and more load is required for $100 \%$ and $200 \%$ elongations. Modulus of blend vulcanizates is higher in the range of $40-50 \%$ reclaim content due to higher crosslink density as observed by Perera et al. [4].

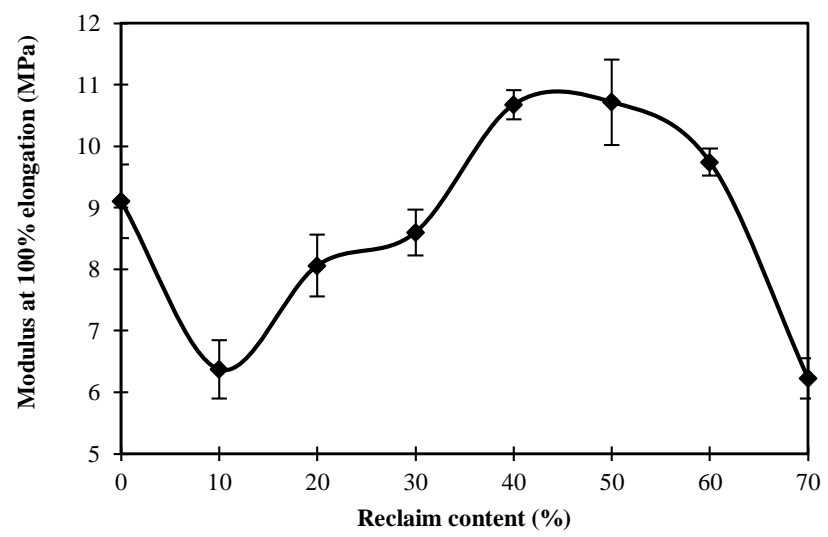

Fig. 2 Variation of modulus at 100\% elongation of virgin NBR / reclaimed NBR blend vulcanizates with reclaim content

Tensile strength of most of the virgin NBR / reclaimed NBR blend vulcanizates is above $12 \mathrm{MPa}$. Tensile strength as well as elongation at break are lowest in the 40:60 virgin NBR / reclaimed NBR blend vulcanizate (Figs. 3 and 4). Tensile strength decreases when the reclaim rubber content in the blend is increased from 10-60\% and agrees with the work of De et al. on carbon black filled virgin rubber (NR) / reclaimed rubber blend vulcanizates [22]. De et al. stated that because reclaimed rubber contains crosslinked gel, when this is blended with virgin rubber much gel remains without dispersing as a continuous matrix with virgin rubber. Such gel remains present as weak sites for stress transmission to its surrounding resulting in a lower tensile strength [23]. Also, Rajan et al. [23] stated that the reclaim particle acts as an obstacle for stress transmission. The stress accumulates on the interface between the reclaimed particle and the matrix and fracture starts from this point. With increasing concentration of reclaim, the concentration of weak spots increases and the tensile strength of the system decreases.

https://doi.org/10.30799/jacs.238.21070301
Variation of elongation at break with reclaimed rubber loading (Fig. 4) is almost like the variation of tensile strength with reclaimed rubber loading (Fig. 3). When hardness increases, elongation at break would decrease and the observed variation in elongation at break could be attributed to the variation in hardness (Fig. 1).

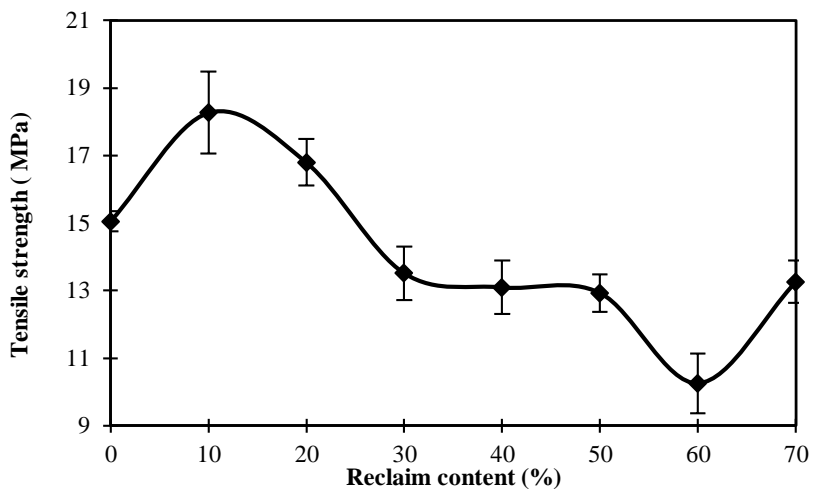

Fig. 3 Variation of tensile strength of virgin NBR / reclaimed NBR blend vulcanizates with reclaim content

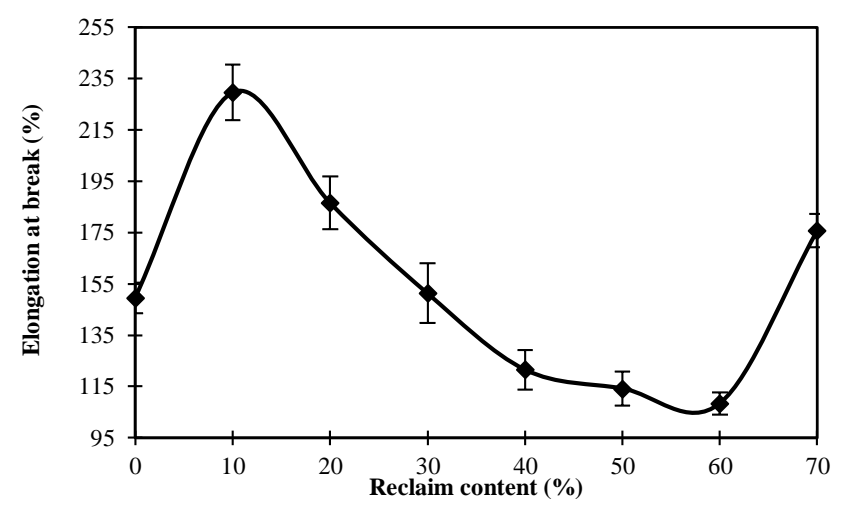

Fig. 4 Variation of elongation at break of virgin NBR / reclaimed NBR blend vulcanizates with reclaim content

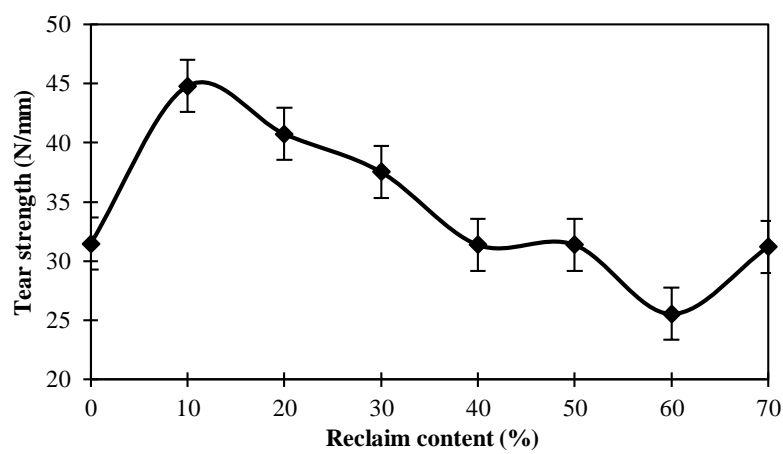

Fig. 5 Variation of tear strength of virgin NBR / reclaimed NBR blend vulcanizates with reclaim content

There is a decrease in tear strength of virgin NBR / reclaimed rubber blend vulcanizates from $10 \%$ to $40 \%$ replacement of virgin NBR with reclaimed rubber (Fig. 5), however the values are above $30 \mathrm{~N} / \mathrm{mm}$. Modulus results indicate that when the reclaimed rubber content is increased from $10 \%$ to $40 \%$, crosslink density increases (Fig. 2) and hence the decrease in tear strength could be attributed to the increase of crosslink density [21]. Similar to tensile strength, tear strength of the 40:60 virgin NBR / reclaimed NBR blend vulcanizate is lower compared to all the other vulcanizates. In a two-phase system, the tear initiated would tend to propagate through the interface, and the extent of propagation depends on interfacial adhesion between the two blend components. The lowest tear strength shown by the 40:60 virgin NBR / reclaimed NBR blend vulcanizate can be attributed to propagation of an initiated crack easily through the weak interface due to poor interfacial crosslinking and hence poor interfacial adhesion indicated by lower maximum torque and (maximum-minimum) torque values of the blend compound [4]. Further, variation of tear strength with increase of reclaim loading takes a similar pattern of tensile strength and is in agreement with the results of the works of Kumnuantip and Sombatsompop [24] and Edirisinghe et al. [25] 


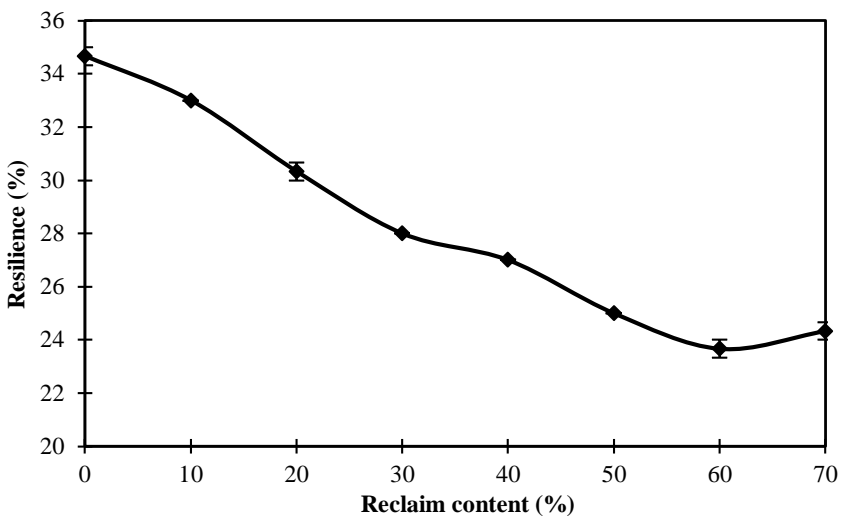

Fig. 6 Variation of resilience of virgin NBR / reclaimed NBR blend vulcanizates with reclaim content

Resilience of all the vulcanizates is below 36\% (Fig. 6). Resilience decreases from $35 \%$ to $24 \%$ when virgin NBR is replaced with reclaimed rubber. This indicates an increase in heat build-up with the increase of reclaimed rubber content. Hysteresis or heat build-up decreases with the increase of crosslink density [21]. Hence hysteresis of the blend vulcanizates should decrease and resilience should increase with the increase of reclaim content from $10 \%$ to $60 \%$. In contrast, resilience has decreased with the increase of reclaim content from $10 \%$ to $60 \%$ and this may also be attributed to reduction in interfacial adhesion between the two phases virgin NR and reclaimed NBR.

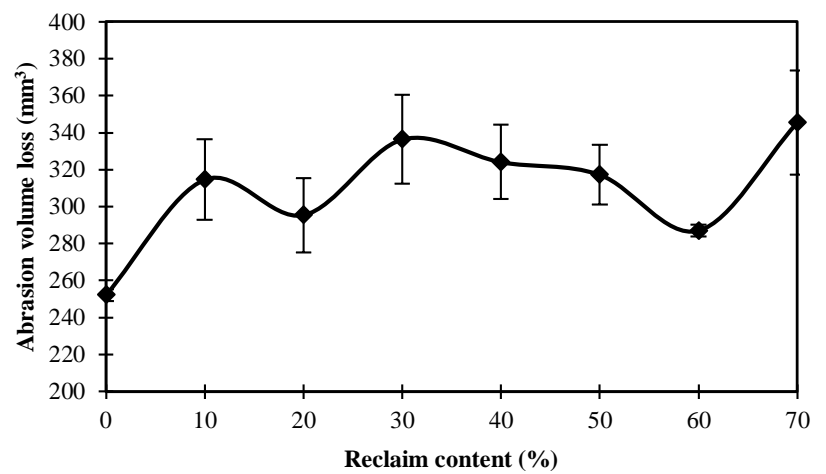

Fig. 7 Variation of abrasion volume loss of virgin NBR / reclaimed NBR blend vulcanizates with reclaim content

Fig. 7 shows that there is no marked difference in abrasion volume loss of the blend vulcanizates prepared with reclaimed rubber. Crosslink density, modulus, hardness, elongation at break and friction coefficient of the vulcanizate are the factors affecting abrasion resistance. As expected, abrasion resistance of the $100 \%$ virgin NBR vulcanizate is greater than that of all the blend vulcanizates. Higher abrasion volume loss of the blend vulcanizates can be attributed to lower interfacial adhesion between the virgin NBR and reclaimed NBR phases governed by the above mentioned factors.

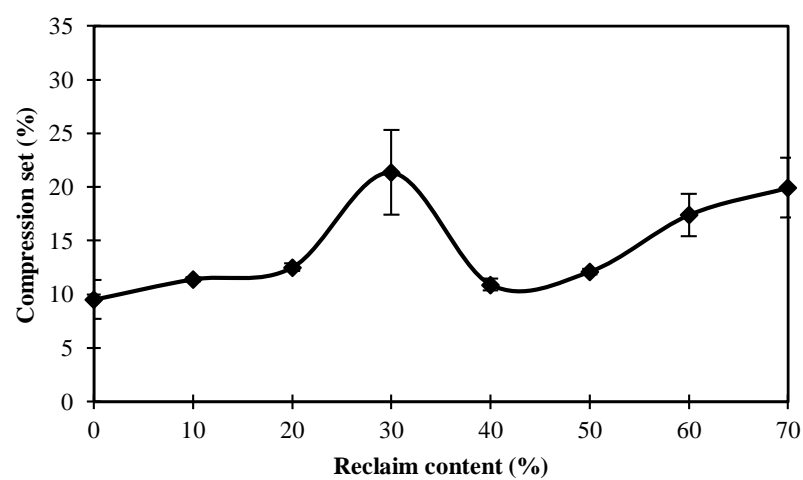

Fig. 8 Variation of compression set of virgin NBR / reclaimed NBR blend vulcanizates with reclaim content

Fig. 8 shows that compression set varies according to a cyclic pattern with the increase of reclaimed rubber content. Compression set of all virgin NBR / reclaimed rubber blend vulcanizates is higher than that of the control. However, compression set of the 50:50 virgin NBR / reclaimed https://doi.org/10.30799/jacs.238.21070301
NBR blend vulcanizate is about $12 \%$ and it is $25 \%$ higher than that of the control. Table 1 gives percentage retention of tensile properties and tear strength of vulcanizates after ageing at $70{ }^{\circ} \mathrm{C}$ for 3 days. Percentage retention of most of the properties is above 100 and indicates that during the ageing period crosslink density has increased due to the presence of active crosslinking sites. Also during ageing, polysulphide crosslinks convert to mono and disulphide crosslinks increasing the crosslink density. All virgin NBR / reclaimed NBR blend vulcanizates exhibit good ageing properties.

Table 1 Percentage retention of tensile properties and tear strength of virgin NBR / reclaimed NBR blend vulcanizates, after air ageing at $70{ }^{\circ} \mathrm{C}$ for 72 hours

\begin{tabular}{lllll}
\hline Sample No. & $\begin{array}{l}\text { Tensile } \\
\text { strength (\%) }\end{array}$ & $\begin{array}{l}\text { Modulus at 100\% } \\
\text { elongation (\%) }\end{array}$ & $\begin{array}{l}\text { Elongation at } \\
\text { break (\%) }\end{array}$ & $\begin{array}{l}\text { Tear strength } \\
(\%)\end{array}$ \\
\hline Control NBR & 101 & 67 & 80 & 120 \\
$\mathrm{~W}_{10}$ & 99 & 101 & 102 & 93 \\
$\mathrm{~W}_{20}$ & 99 & 113 & 111 & 87 \\
$\mathrm{~W}_{30}$ & 103 & 102 & 103 & 89 \\
$\mathrm{~W}_{40}$ & 99 & 119 & 114 & 110 \\
$\mathrm{~W}_{50}$ & 115 & 119 & 98 & 125 \\
$\mathrm{~W}_{60}$ & 129 & 113 & 83 & 144 \\
$\mathrm{~W}_{70}$ & 104 & 168 & 133 & 115 \\
\hline
\end{tabular}

\subsection{Swelling Behaviour of NBR Blend Vulcanizates}

Variation of percentage swelling of vulcanizates with novel reclaimed rubber content is shown in Fig. 9.

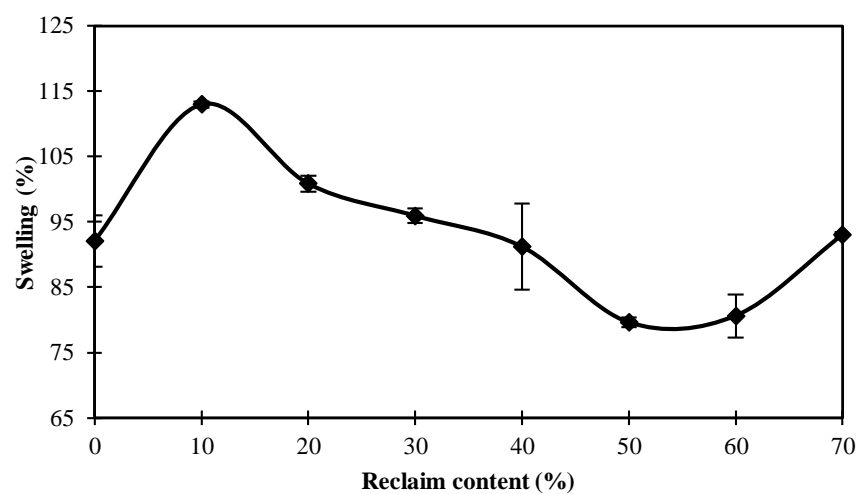

Fig. 9 Variation of percentage swelling of virgin NBR / reclaimed NBR blend vulcanizates with reclaim content

As expected, variation of percentage swelling in toluene of the vulcanizates with novel reclaim content (Fig. 9) is opposite to that of modulus at $100 \%$ elongation (Fig. 2). Resistance to swelling is higher in the vulcanizate containing 50\% reclaimed rubber in comparison to that of the control and this could be attributed to the higher crosslink density indicated by the results of modulus at $100 \%$ elongation.

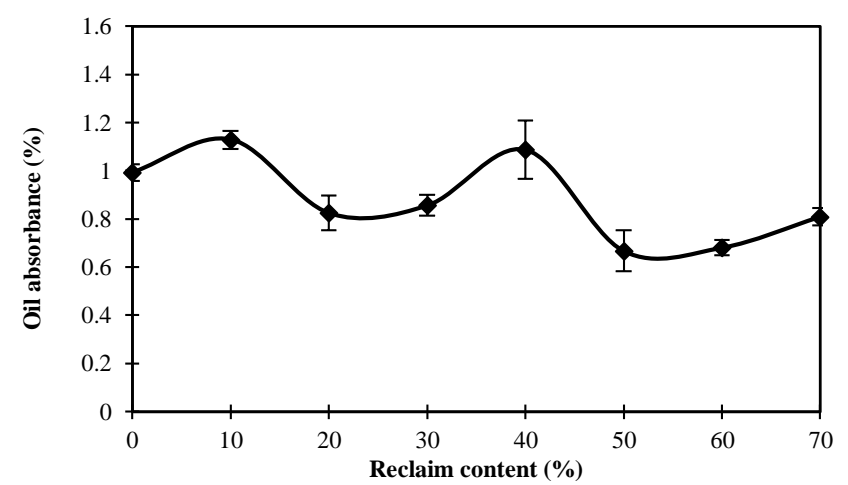

Fig. 10 Variation of percentage oil absorbance of virgin NBR / reclaimed NBR blend vulcanizates with reclaim content

\subsection{Oil Absorbance of NBR Blend Vulcanizates}

Fig. 10 shows that the percentage oil (ASTM oil No. 3) absorbance of virgin NBR / reclaimed NBR blend vulcanizates varies according to a cyclic pattern with reclaimed rubber content. Percentage swelling values of the vulcanizates are in between $0.6 \%$ and $1.2 \%$. Percentage oil absorbance is also lowest in the 50:50 virgin NBR / reclaimed NBR blend vulcanizate and could be attributed to increased crosslink density as in the case of swelling in toluene. 


\section{Conclusion}

Replacement of $50 \%$ of virgin NBR with reclaimed NBR in blend vulcanizates retains about $71-86 \%$ of tensile strength, elongation at break and resilience. Hardness, modulus, tear strength, abrasion volume loss and compression set increases by $7 \%, 17 \%, 8 \%, 26 \%$, and $27 \%$, respectively. Percentage retention of tensile properties and tear strength of virgin NBR / reclaimed NBR vulcanizates after ageing are similar to those of the control vulcanizate. In addition, replacement of $50 \%$ virgin NBR with reclaimed NBR in blend vulcanizate increases swelling resistance in toluene and resistance to oil absorption in ASTM oil No.3 by $14 \%$ and $32 \%$, respectively. Hence, it is concluded that the reclaimed compounded NBR latex waste could be a suitable component to blend with virgin NBR in the production of oil seal components.

\section{Acknowledgments}

The authors would like to thank Rubber Research Institute of Sri Lanka for providing vulcanizing and testing facilities. Holcim Lanka (Pvt.) Ltd. is gratefully acknowledged for supplying the compounded NBR latex waste.

\section{References}

[1] H. Ismail, D. Galpaya, Z. Ahmad, Comparison of properties of polypropylene (PP)/virgin acrylonitrile-butadiene rubber (NBRv) and polypropylene (PP)/recycled acrylonitrile-butadiene rubber (NBRr) blends, Polym. Plast. Technol. Eng. 48(4) (2009) 440-445.

[2] N.Z. Noriman, H. Ismail, The effects of electron beam irradiation on the thermal properties, fatigue life and natural weathering of styrene-butadiene rubber/recycled acrylonitrile-butadiene rubber blends, Mater. Design. 32(6) (2011) 3336-3346.

[3] M. Rezaei Abadchi, A. Jalali Arani, H. Nazockdast, Partial replacement of NR by GTR in thermoplastic elastomer based on LLDPE/NR through using reactive blending: Its effects on morphology, rheological, and mechanical properties, J. Appl. Polym. Sci. 115(4) (2010) 2416-2422.

[4] K.I.D.P. Perera, D.G. Edirisinghe, L. Karunanayake, Characterization of blends of virgin nitrile rubber and compounded nitrile rubber latex waste reclaimed with urea. Part 1: Cure characteristics, Prog. Rub. Plast. Recycl. Tech. 37(2) (2021) 115-130.

[5] S.K. De, Re-use of ground rubber waste-A review, Prog. Rubber Plast. Recycl. Technol. 17(2) (2001) 113-126.

[6] A.K. Naskar, A.K. Bhowmick, S.K. De, Melt-processable rubber: Chlorinated waste tire rubber-filled polyvinyl chloride, J. Appl. Polym. Sci. 84(3) (2002) 622-631.

[7] S. Ramarad, M. Khalid, C.T. Ratnam, A.L. Chuah, W. Rashmi, Waste tire rubber in polymer blends: A review on the evolution, properties and future, Prog. Mater. Sci. 72 (2015) 100-140.

[8] D.G. Edirisinghe, M.I. De Silva, J.K. Premachandra, A novel reclaiming agent for ground rubber tyre (GRT). Part II: Property evaluation of virgin natural rubber
(NR)/novel reclaimed GRT revulcanisates, Prog. Rubber Plast. Recycl. Tech. 27(3) (2011) 161-176.

[9] M. Myhre, D.A. Mackillop, Modification of crumb rubber, Paper presented at a meeting of the Rubber Division, ACS, Cleveland, 17-20 October, 1995, paper 21.

[10] A.N. Theodore, R.A. Pett, D. Jackson, Cure and mechanical behavior of elastomeric compounds containing devulcanized materials, Rubber World 218(2) (1998) 23-25.

[11] M. Nuzaimah, S.M. Sapuan, R. Nadlene, M. Jawaid, Effect of surface treatment on the performance of polyester composite filled with waste glove rubber crumbs, Waste Biomass Valori. 25 (2020) 1-4.

[12] X. Zhang, X. Zhu, M. Liang, C. Lu, Improvement of the properties of ground tire rubber (GTR)-filled nitrile rubber vulcanizates through plasma surface modification of GTR powder, J. Appl. Polym. Sci. 114(2) (2009) 1118-1125.

[13] H. Ahmad, H.A. Ismail, A. Rashid, ENR-50 compatibilized natural rubber/recycled acrylonitrile-butadiene rubber blends, Sains Malays. 44(6) (2015) 835-842.

[14] N.Z. Noriman, H. Ismail, A.A. Rashid, Properties of styrene-butadiene rubber/recycled acrylonitrile-butadiene rubber (SBR/NBRr) blends: Effect of the addition of trans-polyoctylene rubber, J. Appl. Polym. Sci. 126(S2) (2012) E56-E63.

[15] N.Z. Noriman, H. Ismail, M.A. Mohd Salleh, M.M. Al Bakri Abdullah, H. Rosniza, Thermal properties of different recycled acrylonitrile-butadiene rubber glove (NBRr) size and its blend ratios on SBR/NBRr blends, Adv. Mater. Res. 795 (2013) 377-382.

[16] N.Z. Noriman, H. Ismail, A.A. Rashid, The effects of different size of recycled acrylonitrile-butadiene rubber (NBRr) and blend ratio on curing characteristics, mechanical and morphological properties of styrene-butadiene rubber/recycled acrylonitrile-butadiene rubber (SBR/NBRr) blends, Iran Polym. J. 18 (2) (2009) 139-148.

[17] N.Z. Nik Yahya, N.N. Zulkepli, H. Ismail, S.S. Ting, M.M. Abdullah, H. Kamarudin R. Hamzah, Properties of natural rubber/styrene butadiene rubber /recycled nitrile glove (NR/SBR/rNBRg) blends: the effects of recycled nitrile glove (rNBRg) particle sizes, Key Eng. Mater. 673 (2016) 151-160.

[18] H. Ismail, Supri, A.M. Yusof, Properties of virgin poly (vinylchloride)/acrylonitrile-butadiene rubber (PVCv/NBR) and waste poly (vinylchloride)/acrylonitrile-butadiene rubber (PVCw/NBR) blends: The effect of blend composition and dynamic vulcanization, Polym. Plast. Technol. Eng. 43(3) (2004) 695-711.

[19] A. Fazli, D. Rodrigue, Waste rubber recycling: A review on the evolution and properties of thermoplastic elastomers, Materials (Basel). 13(3) (2020) 782

[20] M. Nuzaimah, S.M. Sapuan, R. Nadlene, M. Jawaid, Recycling of waste rubber as fillers: A review, IOP Conf. Series: Materials Science and Engineering 368(1) (2018) 012016.

[21] A.Y. Coran, Science \& Technology of Rubber, F.R. Eirich (Ed.), Rubber Division of the ACS, Chap. 7, Academic division, Inc. Ltd., London, 1978.

22] B. Adhikari, D. De, S. Maiti, Reclamation and recycling of waste rubber, Prog. Polym. Sci. 25(7) (2000) 909-948.

[23] V.V. Rajan, W.K. Dierkes, R. Joseph, J.W.M. Noordermeer, Science and technology of rubber reclamation with special attention to NR-based waste latex products, Prog. Polym. Sci. 31 (2006) 811-834.

[24] C. Kumnuantip, N. Sombatsompop, Effect of reclaimed rubber content in NR / carbon black vulcanizates using microwave irradiation system, ANTEC Thailand, 2005, pp.3211-3215.

[25] D.G. Edirisinghe, Chemical modification of rubber waste and characterization of their blends with natural rubber, Ph.D. thesis, University of Moratuwa, Sri Lanka, 2012. 